\title{
Bromodeoxyuridine DNA labelling reveals host and parasite proliferation in a fish-myxozoan model
}

\begin{tabular}{|r|l|}
\hline Journal: & Journal of Fish Diseases \\
\hline Manuscript ID & JFD-2017-220.R1 \\
\hline Manuscript Type: & Original Manuscript \\
\hline Date Submitted by the Author: & n/a \\
\hline Complete List of Authors: & $\begin{array}{l}\text { Estensoro, Itziar; Instituto de Acuicultura de Torre de la Sal (CSIC), Fish } \\
\text { Pathology } \\
\text { Pérez-Cordón, Gregorio; Cryptosporidium Reference Unit, Public Health } \\
\text { Wales Microbiology } \\
\text { Sitjà-Bobadilla, Ariadna; Instituto de Acuicultura de Torre de la Sal (CSIC), } \\
\text { Fish Pathology } \\
\text { Piazzon, María Carla; Instituto de Acuicultura de Torre de la Sal (CSIC), } \\
\text { Fish Pathology }\end{array}$ \\
\hline Keywords: & \begin{tabular}{l} 
Enteromyxum leei, Sparus aurata, pcna, immunohistochemistry, intestine \\
\hline
\end{tabular} \\
\hline
\end{tabular}


1 Bromodeoxyuridine DNA labelling reveals host and parasite proliferation in a fish-

2 myxozoan model

3 Running title: Intestinal host and parasite proliferation

4 Itziar Estensoro $^{1 \#}$, Gregorio Pérez-Cordón ${ }^{1,2 \#}$, Ariadna Sitjà-Bobadilla ${ }^{1 \oplus}$, María Carla

5 Piazzon $^{1}$

$6{ }^{\#}$ Contributed equally.

$7 \quad{ }^{1}$ Fish Pathology Group, Instituto de Acuicultura Torre de la Sal, Consejo Superior de

8 Investigaciones Científicas, 12595 Ribera de Cabanes, Castellón, Spain

$9 \quad{ }^{2}$ Cryptosporidium Reference Unit, Public Health Wales Microbiology, Singleton

10 Hospital, Swansea, SA2 8QA, UK

Corresponding author: Ariadna Sitjà-Bobadilla

ఏ ariadna.sitja@csic.es

\section{Acknowledgements}

The authors thank J. Monfort and L. Rodríguez for histological processing, M.A.

17 González for technical assistance with gene expression analyses and R. del Pozo for technical assistance with fish husbandry and samplings. This work has been carried out with financial support from Spanish MINECO under projects AGL2009-13282 and AGL2013-48560-R. Additional funding was provided by the European Union, through the Horizon H2020 research and innovation program under grant agreement 634429 (ParaFishControl). This publication reflects only the authors' view and the European 
24 contained therein. Further support was provided by Generalitat Valenciana

25 (PROMETEOII/2014/085). IE was contracted under APOSTD/2016/037 grant by the

26 "Generalitat Valenciana", GP-C under "Juan de la Cierva" program of Ministerio de

27 Ciencia e Innovación (JCI-2011-09438) and MCP under CSIC PIE project no.

$28 \quad 201740 E 013$ and MINECO FPDI-2013-15741.

29 Conflict of interests. The authors declare that they have no conflict of interest.

30 


\section{Abstract}

32 Enteromyxum leei is a myxozoan parasite responsible for enteritis in gilthead sea bream

33 (Sparus aurata). The parasite proliferates in the paracellular space of the intestinal 34 epithelium and induces an inflammatory reaction. In order to assess intestinal cell 35 turnover and parasite proliferation, fish were infected with the parasite by anal 36 intubation and after 17 and 64 days, the cell proliferative marker bromodeoxyuridine 37 (BrdU) was administered and, after 24 hours, tissue samples were taken for immunohistochemical detection. Parasite exposure induced increased epithelial and immune cell proliferation in all intestinal segments at all time points, even before 40 parasite establishment. This increased turnover was triggered early after intubation and 41 mainly at a local level, as shown by an increased proliferating cell nuclear antigen 42 (рсnа) gene expression only at the posterior intestine after 17 days (not found in lymphohaematopietic organs). Incorporation of BrdU in parasite secondary and tertiary daughter cells indicated that parasite endogeny is not by schizogonial division, which uses de novo synthesis pathway of pyrimidines. Altogether, BrdU immunolabelling and pcna gene expression showed the rapid proliferative response of the fish intestines upon a myxozoan infection and how this response is effectively triggered even before the parasite reaches or establishes in the site.

Keywords: Enteromyxum leei, Sparus aurata, pcna, immunohistochemistry, intestine 


\section{Introduction}

The regenerative capacity of the intestinal epithelium, by means of a strict control of proliferation and programmed cell death, plays a central role in the maintenance of the intestinal homeostasis. The process of restoration of the epithelium is well documented in vertebrates, in which the mucosa is entirely regenerated through a continuous cycle of cell proliferation, migration and differentiation over the entire crypt-villus axis at an extraordinary high rate (Crosnier et al. 2006; Faro et al. 2009; Wallace et al. 2005; Wang et al. 2010). Epithelial renewal occurs through division of stem cells at the bottom of the intestinal folds, the inter-villus pocket region. From there, transitamplifying and differentiated cells migrate towards the apical region of the folds, where apoptosis and shedding take place. The study of the intestinal epithelium turnover in the zebrafish model has demonstrated a great similarity between the teleostean and mammalian mucosal regeneration, the latter presenting a slower epithelial restitution in order to restrain excessive expansion and reduce susceptibility to carcinogenic transformations (Faro et al. 2009; Wang et al. 2010).

Fish intestinal remodelling can be affected by or can compensate the distress of the intestinal homeostasis provoked by diet interventions (Bakke-McKellep et al. 2007; Chikwati et al. 2013; Yoshida et al. 2016), radiation (Johnson et al. 1970), intestinal resection (Schall et al. 2015), adaptation to salinity changes (Takahashi et al. 2007; Takahashi et al. 2006), or pathogens (Dezfuli et al. 2012; Dezfuli et al. 2016b; Hemmer et al. 1998; Ronza et al. 2011). Inflammation is generally considered a beneficial response to tissue damage for its induction of a localized repair response. Such an epithelial repair and healing process involves local recruitment and/or proliferation of immune-relevant cells, controlled proliferation of stem cells in the fold base and 
turnover of damaged epithelial cells, in order to restore the epithelial barrier integrity.

The innate cellular immune response to parasites in fish intestines, whether or not leading to enteritis, mainly consists of an inflammatory reaction involving granular tissue formation and infiltration of leukocytes and macrophages, in microparasite infections (Sitjà-Bobadilla et al. 2016), as well as in helminthiasis (Dezfuli et al. 2016a). Cell proliferation in parasitized intestines plays a key role during the host immune response, as it may be decisive for the pathogenesis exerted by each parasite and, thus, be partially responsible for the success of either parasite establishment or its rejection.

Enteromyxum leei is a myxozoan parasite that infects the intestinal tract of gilthead sea bream, among many other species, causing chronic desquamative enteritis. Myxozoans are metazoan microscopic parasites, which constitute a clade of highly derived cnidarians (Foox and Siddall 2015). Enteromyxosis in this fish host eventually leads to emaciation, cachexia and immunosuppression, which enhances susceptibility to opportunistic pathogens and causes high mortality rates during outbreaks in aquaculture facilities (Davey et al. 2011; Palenzuela 2006; Sitjà-Bobadilla and Palenzuela 2012). The horizontal fish-to-fish transmission of Enteromyxum spp. and the lack of effective treatments pose a serious threat for fish farming, especially in the case of gilthead sea bream massively established in Mediterranean sea cages (Athanassopoulou et al. 2009; Colorni and Padrós 2011; Rigos and Katharios 2010; Sitjà-Bobadilla 2004; SitjàBobadilla and Palenzuela 2012). E. leei stages reach the fish intestine through the digestive tract and penetrate the epithelium, where proliferative and sporogenic stages multiply in the paracellular space (Diamant et al. 1994; Diamant and Wajsbrot 1997). The parasite quickly multiplies and colonizes other sites of the intestinal tract or infects other fish hosts, using the desquamated epithelial material that withholds parasite stages for partial protection in the intestinal lumen first and finally in the seawater when 
parasite stages are released with the fish faeces. Thus, epithelial cell proliferation, turnover and shedding in the gilthead sea bream intestine are expected to be harshly affected during E. leei-induced enteritis, but have not been previously evaluated. Previous studies on gilthead sea bream have reported transcriptional modulation of genes involved in the intestinal cell differentiation and proliferation, and epithelial integrity, damage and repair during E. leei-induced enteritis (Calduch-Giner et al. 2012; Davey et al. 2011; Pérez-Sánchez et al. 2013; Sitjà-Bobadilla et al. 2008).

This study is focused on the intestinal cell proliferation in a teleost species during an enteric myxozoan experimental infection by means of 5-bromo-2'deoxyuridine (BrdU) in vivo labelling and by proliferating cell nuclear antigen ( $p c n a)$ gene expression at intestinal and systemic levels.

\section{Material and methods}

\section{Animal care, experimental design and sampling procedure}

Clinically healthy juvenile gilthead sea bream were obtained from a commercial fish hatchery. Upon arrival to the facilities of the Instituto de Acuicultura Torre de la Sal (IATS), they were checked to be SPF (E. leei-free) by routine molecular and histological diagnostic techniques, and grown in an open flow system with $5 \mu \mathrm{m}$-filtered and UV-irradiated seawater (37.5\%o salinity). Day length corresponded to the natural changes at our latitude $\left(40^{\circ} 5 \mathrm{~N} ; 0^{\circ} 10^{\prime} \mathrm{E}\right)$, and water temperature was maintained between $18{ }^{\circ} \mathrm{C}$ and $25^{\circ} \mathrm{C}$. The oxygen content of water was kept above $85 \%$ saturation, and unionized ammonia remained below toxic levels $(<0.02 \mathrm{mg} / \mathrm{l})$. Fish were fed $\mathrm{ad}$ libitum a commercial diet (BioMar, Palencia, Spain). 
127 (Estensoro et al. 2010). Briefly, 36 fish (average initial weight $=60.5 \mathrm{~g}$ ) were intubated with $0.5 \mathrm{ml}$ of $E$. leei infected-intestinal scrapings (recipient group, RCPT) and 36 fish (average initial weight $=58.7 \mathrm{~g})$ were intubated with the same volume of PBS (control group, CTRL). At $17($ time point $=\mathrm{t} 1)$ and $64($ time point $=\mathrm{t} 2)$ days post intubation (dpi), 7 fish from both the CTRL and RCPT groups were intracoelomically injected with 5-bromo-2'-deoxyuridine (BrdU, Sigma, St. Louis, MO, USA) in Hank's Balance Salt Solution (Gibco, USA) / dimethyl sulfoxide (Sigma) (HBSS/DMSO,1:5) at a dose of $100 \mathrm{mg} \mathrm{BrdU/kg}$ fish weight.

Twenty four hours after BrdU injection, fish were sacrificed by overexposure to the anaesthetic MS-222 (Sigma, St. Louis, MO, USA) and tissue samples of anterior (AI, immediately after the pyloric caeca), middle (MI, equidistant from $\mathrm{AI}$ and $\mathrm{PI}$ ), and posterior (PI, immediately before the rectum) intestine were taken, fixed in $4 \%$ paraformaldehyde and processed for paraffin embedment following routine histological procedures for parasite diagnosis and immunohistochemical localization of BrdU in 4 $\mu$ m-thick tissue sections. Pieces of head kidney (Hk), spleen (Spl) and PI were excised from the same fish, rapidly frozen in liquid nitrogen and stored at $-80^{\circ} \mathrm{C}$ until RNA extraction. 13282-C02-01. 
152 Parasite diagnosis was performed on Giemsa stained AI, MI, and PI intestine segments.

153 Infection intensity in each segment was semiquantitatively evaluated following a 154 conventional scale from $1+$ to $6+$, with the following ranges: $1+=1-5 ; 2+=6-10 ; 3+=$ $15511-25 ; 4+=26-50 ; 5+=51-100 ; 6+>100$ parasite stages per microscope field 156 observation at 120x. E. leei stages were classified as spores, sporoblasts and 157 proliferative stages, the latter corresponding to stages one to three described in 158 (Álvarez-Pellitero et al. 2008). A fish was considered positive for infection, when the parasite was found at least in one intestinal segment.

\section{Immunohistochemical detection of Bromodeoxyrudine (BrdU)}

BrdU antigens in tissue sections on SuperfrostPlus slides (Menzel-Gläser) were retrieved by heating in a pressure-cooker for $15 \mathrm{~min}$ in $10 \mathrm{mM}$ sodium citrate buffer (pH 6.0). After 30 min incubation in $\mathrm{HCl} 2 \mathrm{~N}$, slides were incubated for one hour with mouse Mab anti-BrdU clone BU-33 (1:500) (Sigma, St. Louis, MO, USA) at room temperature (RT). A secondary biotinylated antibody (1:200) (VECTOR Labs.) was added for one hour (RT) followed by incubation with avidin-biotin-peroxidase complex (VECTOR Labs.) for $30 \min (\mathrm{RT})$. Bound peroxidase was visualized with 3,3'diaminobenzidine tetrahydrochloride (Sigma, St. Louis, MO, USA) and sections were counterstained with Gill's haematoxylin, dehydrated and mounted in DPX. and intestinal segment (AI, MI and PI observed at 500× magnification) ten random microscopical fields, regardless of the presence or absence of the parasite, were photographed with an Olympus DP70 camera (12.5 million pixels) connected to a Leitz 
Dialux 22 light microscope. Immunoreactive cells were detected and quantified using ImageJ software (open-source Java-based imaging program). Labelled and non-labelled parasite stages were counted and their ratio calculated. Images were not manipulated.

\section{Proliferating cell nuclear antigen (pcna) gene expression}

Head kidney, spleen and posterior intestine RNA was extracted using the MagMAX ${ }^{\mathrm{TM}}$ 96 total RNA isolation kit (Applied Biosystems, Foster City, CA, USA). Reverse transcription was performed on $500 \mathrm{ng}$ of total RNA using random decamers and the High-Capacity cDNA Archive kit (Applied Biosystems) following manufacturer's instructions. Negative control reactions without reverse transcriptase were included. Real-time quantitative PCR was carried out with the CFX96 Connect $^{\mathrm{TM}}$ Realdata acquired during the extension phase were normalized by the delta-delta $\mathrm{Ct}$ method 
Statistical analysis

203

204

The number of BrdU immunoreactive cells in the intestine of CTRL and RCPT groups was statistically analysed. For each intestinal segment, the differences between both groups and the differences between $\mathrm{t} 1$ and $\mathrm{t} 2$ for each group/intestinal segment were analysed by Student's $t$ test. When the test of normality or equal variance failed, a Mann-Whitney U Sum test was applied instead. A one-way ANOVA followed by Student-Newman-Keuls was used to analyse the differences within each group for each time and the differences between each fish category for a given intestinal segment. Data that failed the normality or equal variance test, were analysed with Kruskal-Wallis oneway ANOVA on ranks followed by Dunn's method. The significance level was set at $P$ $<0.05$. All statistical analyses were performed using Sigma Stat software (SPSS Inc., Chicago, IL, USA).

Results

\section{Disease outcome}

After 17 dpi (t1), E. leei was mainly detected at the PI with an infection prevalence of $42.9 \%$ (3 fish out of 7) and with a mean infection intensity of 2+. At the AI, prevalence of infection was $14.3 \%$ ( 1 fish out of 7 , with $2+$ intensity of infection) and no fish were infected at the MI at this time point. At 64 dpi (t2), prevalence of infection at the PI reached $85.7 \%$ (6 fish out of 7) with a mean infection intensity of $5.2+$ and the parasite 
fish out of 7) was found at the AI with a mean infection intensity of $3.3+$, and a $14.3 \%$ of prevalence of infection (1 fish out of 7) was found at the MI with the maximum infection intensity. All fish with an established infection at the AI and/or MI, were also infected at the PI. Parasites found at 17 dpi were presporogonic proliferative stages, whereas at 64 dpi, sporoblasts and spores were also observed (Table 1, Fig. 1).

\section{BrdU immunoreactivity}

BrdU incorporation to nuclear DNA was successfully detected in samples taken $24 \mathrm{~h}$ after injection, mainly in enterocytes (Fig. 1, Fig. 2). Yet, distribution of immunoreactive epithelial cells was not only restricted to inter-villus pockets, as proliferating cells were detected along the entire mucosal folds in CTRL and RCPT fish, regardless of the intestinal section. In addition, abundant BrdU immunoreactive cells were detected in the lamina propria-submucosa of RCPT fish, even in non-infected intestinal sections. The size and morphology of the nuclei indicate that these cells are mainly granulocytes and some lymphocytes.

Mean counts of BrdU immunoreactive host cells at t1 were significantly higher in all intestinal segments of RCPT fish than in those of CTRL fish, and the greatest difference was found in the MI (Fig. 3). At t2, the number of BrdU immunoreactive cells was also higher in RCPT than in CTRL fish, though only statistically significant at the PI (Fig. 3). However, within each fish group, no significant differences were detected for the host cell counts among intestinal segments, nor between $\mathrm{t} 1$ and $\mathrm{t} 2$ within fish groups and intestinal segments (Fig. 3).

As cell proliferation in non-parasitized intestinal segments (AI and MI) seemed to be affected by the presence of the parasite at the PI, $\mathrm{t} 1$ and $\mathrm{t} 2$ data were merged for 
each intestinal segment, and cell counts of CTRL fish were compared with those of

252

253

254

255

256

257

258

259

260

261

262

263

264

265

266

267

268

269

270

271

272

273

274

275

three categories of RCPT fish: a) fish with non-parasitized AI/MI segments and also no parasite at the PI (NP), b) fish with non-parasitized AI/MI segments, but with parasitized PI (NP-PAR PI), and c) fish with parasitized AI/MI segments and also parasitized PI (PAR). As shown in Fig. 4, the number of BrdU labelled cells was significantly higher in parasitized PI and AI than in intestines from CTRL fish. However, no significant differences were found between CTRL intestines and nonparasitized segments of RCPT fish, even though they had higher number of BrdU labelled cells than CTRL fish. Furthermore, at the non-parasitized MI, cell counts were higher in fish in which the neighbouring PI segment was parasitized. Thus, an increasing trend was clear from CTRL to PAR fish, especially in the MI.

Moreover, BrdU labelling was also detected in proliferating parasite stages, mainly secondary and tertiary daughter cells (Fig. 1). The mean ratio of BrdU immunoreactive parasites/total parasites in the PI was 0.70 at $\mathrm{t} 1$ and 0.76 at $\mathrm{t} 2$, whereas in the $\mathrm{AI}$ and $\mathrm{MI}$ at $\mathrm{t} 2$ it was 0.70 and 0.80 , respectively.

\section{pcna gene expression}

At the PI segment, pcna gene expression was significantly higher in RCPT fish than in CTRL ones, only at t1. By contrast, no statistically significant differences were found for the pcna gene expression in the studied lymphohaematopoietic tissues (head kidney and spleen) (Fig. 5).

\section{Discussion}


Enteromyxum leei intestinal infection followed a postero-anterior progress, as

277

278

279 previously described in gilthead sea bream, being the PI the main target site for the parasite and the MI the last and less infected intestinal portion (Cuadrado 2009; Estensoro et al. 2010; Fleurance et al. 2008). The per anal infection route provided a reliable source of infected fish, whose prevalence of infection at the given water temperature was similar to previous experimental infections by this same route (Estensoro et al. 2014; Estensoro et al. 2010; Pérez-Cordón et al. 2014). In the current experimental infection, the highest prevalences and intensities of infection were found at the PI at both samplings, indicating this was the first intestinal segment where the infection was established. At t2 (64 dpi), the parasite infection had not only extended to more fish along their intestinal segments, but also parasite sporogenesis had begun. In order to assess intestinal cell turnover and parasite proliferation, the cell proliferative marker BrdU was administered. BrdU is incorporated into synthetizing nuclear DNA during the S-phase of the cell cycle and can be later immunohistochemically detected (Walsh and Eckert 2014). Since Gratzner (1982) described a monoclonal antibody to BrdU, this technique has proven to be very useful in many research fields to assess cell proliferation in normal tissues and tumours and to trace cells during development and differentiation (Goodlad 2017). This technique has been applied previously in teleost fish to evaluate the effects of gastrointestinal distress (Dezfuli et al. 2016b; Schall et al. 2015; Takahashi et al. 2007; Yoshida et al. 2016), but has not been used for sparids or for the study of host-parasite interactions involving myxozoans. Distribution of proliferating intestinal epithelial cells in gilthead sea bream was quite scattered throughout the mucosal folds, even in CTRL tissues, indicating elevated tissue renewal rates since no signs of hyperplasia were observed. E. leei infection clearly provoked a significant increase of intestinal epithelial cell proliferation 
in RCPT compared to CTRL fish. This increased proliferation was more pronounced at early infection times (17 dpi). The intestinal epithelium exhibits the fastest renewal rate of all vertebrate tissues in order to preserve its essential barrier function. More specifically, in teleosts, enterocyte turnover rates are the highest, favouring a rapid repair and restitution of the epithelium in the pathogen-rich water environment (Wang et al. 2010). Epithelial turnover (proliferation, differentiation and apoptosis) ensures the anatomical barrier integrity, and can be considered part of the innate immunity since pathogens attached to the lining epithelium get shed and are eliminated with surface cells prior to their penetration and invasion (Kim et al. 2010; Liempi et al. 2016). This protective mechanism, already reported in mammals, is engaged for example upon infection, since the acceleration of the epithelial turnover helps to expel the parasitic nematode Trichuris trichuria from murine intestines (Cliffe et al. 2005), or pathogenic Escherichia coli from human urothelium (Mysorekar et al. 2002), or Trypanosoma cruzi from human placental trophoblasts (Droguett et al. 2017). Increased intestinal epithelial turnover has also been described in several protozoan infections (Buret et al. 1990) and basal and luminal epithelial proliferation of mouse prostates is induced by Toxoplasma gondii infection (Colinot et al. 2017). These mechanisms are poorly documented in teleosts and no reports exist in this regard about myxozoan infections. During common carp intestinal infection with the coccidian Goussia carpelli, an increase in the epithelial turnover rate occurred in order to counteract the epithelial destruction exerted by the parasite and regenerate the tissue (Hemmer et al. 1998). At initial phases of Enteromyxum scophthalmi infection in turbot, an increase in epithelial apoptosis prior to desquamation was observed, which was attributed either to the direct damage on the enterocytes by the parasite and/or its secretions, or to an increase in epithelial cell turnover in order to expel the parasite (Losada et al. 2014). Turbot enteromyxosis ends 
up in lethal catarrhal enteritis and the parasite is much more pathogenic in this host than

E. leei in gilthead sea bream. Transcriptomic analyses of turbot enteromyxosis revealed a complex cell death/proliferation balance, but in the pyloric caeca of infected turbot, tissue repair and cell proliferation genes (including pcna) were significantly upregulated (Robledo et al. 2014). Similarly, a complex interplay between host and/or parasite mediated apoptosis and cell proliferation was reported for the gene expression in E. leei-infected PI of gilthead sea bream, in which the regenerative action was evidenced by the up-regulation of genes involved in cell proliferation (Calduch-Giner et al. 2012; Davey et al. 2011). RCPT, compared to CTRL fish, at the early time after exposure to the parasite. MI was the only non-parasitized intestinal section of all the sampled fish at $\mathrm{t} 1$, when total prevalence of infection reached $42.9 \%$. Intestines of fish histologically diagnosed as non-infected, and non-infected MI adjacent to parasitized segments, even presented significantly increased numbers of proliferating cells. Thus, exposure to E. leei seemed to trigger epithelial cell renewal in the intestine, even before the parasite attached and penetrated the lining epithelium or tissue damage was observed. This became more evident by merging $\mathrm{t} 1$ and $\mathrm{t} 2$ data (Fig. 4). The highest differences in the number of Hemmer et al. (1998) reported increased epithelial cell proliferation in common carp only associated to damaged intestinal epithelia by G. goussia infection and 
affected ones. Cell proliferation in teleost intestines during the immune response to helminths is restricted to wounds and parasite attachment sites (Dezfuli et al. 2016a). Nevertheless, the prominent enterocyte renewal in gilthead sea bream was not restricted to injured and parasitized sites, pointing towards an early parasite-induced immunoregulation, in line with the observed cell proliferation among inflammatory infiltrates of RCPT fish. Of note, the systemic recruitment of migrating immune cell populations is locally complemented by in situ cell proliferation at the infection site. Previous studies demonstrated an early expression of pro-inflammatory cytokines at the PI occurring simultaneously with the current early cell proliferation (Pérez-Cordón et al. 2014). Regulation of epithelial cell proliferation in response to macroparasite infections is associated to a pro-inflammatory immune response in murine intestines (Cliffe et al. 2005) and in teleost skin (Kania et al. 2010), involving cytokines such as TNF $\alpha$ and IL1 $\beta$. Furthermore, studies relate regulation of epithelial cell proliferation to IFN- $\gamma$ production, which in turn modulates interleukin synthesis by macrophages (Artis et al. 1999; Cliffe et al. 2005), and IFN-related pathways were up-regulated and played a main role at systemic as well as intestinal level during enteromyxosis in gilthead sea bream (Davey et al. 2011) and turbot (Ronza et al. 2016). Previous studies found a local shift towards an anti-inflammatory cytokine response at 64 dpi (Pérez-Cordón et al. 2014), supporting the gene expression reported for 113-day chronic exposure (SitjàBobadilla et al. 2008). This shift, in order to protect the fish intestine from an excessive inflammatory response, was currently reflected by means of BrdU immunohistochemistry as a slight decrease of the intestinal epithelial cell proliferation in $\mathrm{t} 2$, at the $\mathrm{AI}$ and $\mathrm{MI}$.

However, since E. leei was directly inoculated into the fish intestine by anal route, we cannot discard that innate mucosal mechanisms were initiated before parasite 
establishment, shortly after inoculation, which might eventually lead to the increase of cell proliferation detected at $17 \mathrm{dpi}$. Induction of urothelial cell proliferation was triggered in mice by pathogenic bacteria attachment and recognition prior to tissue damage, together with promotion of an early pro-inflammatory immune response (Mysorekar et al. 2002).

Notably, no differences in epithelial cell proliferation were found among intestinal segments within any of the experimental groups at any of the sampling points, though the parasite affected segments with different intensity and prevalence of infection. The PI was the segment with the highest abundance of BrdU immunoreactive cells in RCPT compared to CTRL fish and with the highest prevalence of infection at 64 dpi. In any case, the role of epithelial cell renewal in expulsing E. leei from the fish intestine was quite limited and ineffective, since all fish except one were parasitized at t2, and PI epithelia were massively invaded by the myxozoan. Susceptibility to dietary induced enteritis in salmonids has been associated to slower enterocyte turnover rates, as in the Atlantic salmon PI (Chikwati et al. 2013) or in the rainbow trout PI (Yoshida et al. 2016). Both fish species counteracted tissue damage at the PI by accelerating enterocyte turnover rates. In the present study, fish were unable to elicit a protective response, though parasite exposure seemed to arouse increased numbers of proliferating intestinal cells. Thus, a parasite-driven modulation process to achieve or maintain a more suitable niche for parasite dwelling (immature enterocytes, modified mucus secretion and microbiota), should not be discarded. This parasite-driven process could be a strategy to increase infectivity by shedding viable parasite stages, which would thereafter infect further intestinal segments and hosts. Immature epithelial cells with impaired absorptive functions spread along the surface of the mucosal folds after the increase of the cell turnover rate during carp coccidiosis (Hemmer et al. 1998), which 
may also not be immunologically competent and thus impair barrier function, antigen presentation or expression of antimicrobial peptides, pathogen recognizing receptors and cytokines (Álvarez-Pellitero 2011). An intestinal epithelial barrier mainly consisting of undifferentiated, immature enterocytes was also observed in salmonids affected by dietary induced enteritis (Bakke-McKellep et al. 2007; Chikwati et al. 2013; Krogdahl et al. 2003). Additionally, modulation of the mucin products in E. leei infected gilthead sea bream intestines was reported (Estensoro et al. 2012; PérezSánchez et al. 2013), which probably involves a shift of the resident and transient microbiota as observed by the decreased bacterial adhesion to the secreted mucus mucins (Estensoro et al. 2013). Eventually, the microbiota might also affect the transit rate of the intestinal epithelial cells, as described in mice (Savage et al. 1981).

The present study also aimed to clarify if the parasite-induced modulation of the intestinal cell proliferation extended further than the parasite's target tissue and affected lymphohaematopoietic organs. Gene expression of pcna, which is necessary for DNA synthesis, both in replication and repair and rises during G1/S phase (Mailand et al. 2013), was analysed. Our results revealed a higher pcna gene expression in RCPT than in CTRL fish only at the intestinal level (PI) in t1, indicating that enhanced cell renewal occurred mainly locally, most likely in an attempt to substitute the infected epithelia and expel the parasite. This local response occurred with higher intensity at the early time after parasite exposure (t1), supporting BrdU immunohistochemical observations and correlating with the shift towards an anti-inflammatory immune response (Pérez-Cordón et al. 2014) restraining cell proliferation in t2. Though non-significantly, the opposite trend of decreased cell proliferation at $\mathrm{t} 1$ and increased proliferation at $\mathrm{t} 2$ was detected in both, Spl and Hk. This would be coherent with an early acute response mainly focused on the innate defence in the intestine, the infection site, whereas adaptive 
immune mechanisms are launched at systemic level, later during the lasting chronic infection. Hence, the haematopoietic proliferation would indicate the onset of the maturation and initiation of the humoral and cellular adaptive response after antigen presentation, according to the massive leukocyte increase (plasma cells/B cells and mast cells) reported in Spl and $\mathrm{Hk}$ of E. leei-infected gilthead sea bream after 40 dpi (Estensoro et al. 2014) and to the reported activation of IFN- $\gamma$ pathway, which promotes antigen presentation through activation of $m h c$ gene expression (Davey et al. 2011). expression do not only indicate cellular replication, but also DNA repair (Chikwati et al. 2013). In addition to the evident damage inflicted by the parasite to the epithelial integrity, cellular stress and damage were reported by means of up-regulated heat shock protein genes in E. leei-infected gilthead sea bream (Sitjà-Bobadilla et al. 2008). Thus, the immunoreactive cells detected in the epithelium might be considered as non-fully differentiated enterocytes, which still retain their replicative capacity, or as cells damaged by the direct effect of the parasite or by the host's inflammatory reaction, which are under repair process.

The life cycle of myxozoans in fish is dominated by proliferative stages composed of a single cell, containing one to several hundred cells within its cytoplasm. The outer cell is referred to as the primary cell or mother cell and the internal cells as nucleus of a myxozoan species, particularly in E. leei young internal daughter cells (secondary and tertiary cells). The proliferative rate of the parasite presented scarce variation along time and segments. However, at the PI, parasite proliferation rate increased at $\mathrm{t} 2$, and MI was the segment with the highest rate, which would be in 
agreement with the fact that MI is the last segment to be invaded by the parasite.

452 Labelling with thymidine analogues has also been used to study the cell cycle of protozoan and metazoan parasites, such as Schistosoma, Leishmania or Trypanosoma (da Silva et al. 2017; Galanti et al. 2012; Mandell and Beverley 2017), and even to track the possible in vitro proliferation of another myxozoan, Enteromyxum scophthalmi (Redondo et al. 2003). However, it cannot be applied for those organisms in which replication does not occur mainly via canonical binary fission (but by schizogony), as for Plasmodium parasites. Schizogony is a common form of asexual division in the Apicomplexa, in which the nucleus divides several times, before the cytoplasm divides into smaller new multiple uninucleate cells (merozoites). These parasites do not incorporate BrdU because they rely only on de novo synthesis of pyrimidines and do not salvage thymidine analogues like BrdU for conversion into nucleotides (Merrick 2015). In most species, two metabolic routes contribute to the intracellular deoxyribonucleotides (dNTP) pool, the de novo and the salvage pathway (Reichard 1988). Within myxozoans, the process of formation of all internal cells has been controversial and referred as endogeny. Some authors have regarded that endogeny occurs through engulfment, followed by mitosis of the internalized cells and not through endogenous budding (Morris 2010). Endogenous budding, though presented as a dogma for many decades, has never been confirmed. In any case, schizogonial division would be discarded by the current results, since BrdU was clearly incorporated into E. leei 471 secondary and tertiary daughter cells. The present study highlights the intense activation of intestinal epithelial cell proliferation, suggesting the involvement of the local immune response, in contrast to the absence of cell proliferation at a lymphohaematopoietic level. This process appears 
475 to be triggered by the exposure of the parasite, but further studies are required to unravel 476 the underlying immune-regulating mechanisms.

477 


\section{References}

Álvarez-Pellitero, P. (2011). Mucosal intestinal immunity and response to parasite infections in ectothermic vertebrates immunology and immune system disorders. Nova Science Publishers Inc (New York).

Álvarez-Pellitero, P., Palenzuela, O., \& Sitjà-Bobadilla, A. (2008) Histopathology and cellular response in Enteromyxum leei (Myxozoa) infections of Diplodus puntazzo (Teleostei). Parasitology International, 57(2), 110-120. doi: 10.1016/j.parint.2007.09.004

Artis, D., Potten, C. S., Else, K. J., Finkelman, F. D., \& Grencis, R. K. (1999) Trichuris muris: Host intestinal epithelial cell hyperproliferation during chronic infection is regulated by interferon- $\gamma$. Experimental Parasitology, 92(2), 144-153. doi: 10.1006/expr.1999.4407

Athanassopoulou, F., Pappas, I. S., \& Bitchava, K. (2009) An overview of the treatments for parasitic disease in Mediterranean aquaculture. In: Basurco B, Rogers C (eds), The use of veterinary drugs and vaccines in Mediterranean aquaculture, vol 86. Options Méditerranéennes : Série A. Séminaires Méditerranéens (pp. 65-83). Zaragoza: CIHEAM

Bakke-McKellep, A. M., Penn, M. H., Salas, P. M., Refstie, S., Sperstad, S., Landsverk, T., Ring ø, E., \& Krogdahl, A. (2007) Effects of dietary soyabean meal, inulin and oxytetracycline on intestinal microbiota and epithelial cell stress, apoptosis and proliferation in the teleost Atlantic salmon (Salmo salar L.). British Journal of Nutrition, 97(4), 699-713. doi: 10.1017/S0007114507381397

Buret, A., Gall, D. G., Nation, P. N., \& Olson, M. E. (1990) Intestinal protozoa and epithelial-cell kinetics, structure and function. Parasitology Today, 6(12), 375380. 
Calduch-Giner, J. A., Sitjà-Bobadilla, A., Davey, G. C., Cairns, M. T., Kaushik, S., \& Pérez-Sánchez, J. (2012) Dietary vegetable oils do not alter the intestine transcriptome of gilthead sea bream (Sparus aurata), but modulate the transcriptomic response to infection with Enteromyxum leei. BMC Genomics, 13, 470. doi: 10.1186/1471-2164-13-470

Chikwati, E. M., Gu, J. N., Penn, M. H., Bakke, A. M., \& Krogdahl, A. (2013) Intestinal epithelial cell proliferation and migration in Atlantic salmon, Salmo salar L.: effects of temperature and inflammation. Cell and Tissue Research, 353(1), 123-137. doi: 10.1007/s00441-013-1631-9

Cliffe, L. J., Humphreys, N. E., Lane, T. E., Potten, C. S., Booth, C., \& Grencis, R. K. (2005) Accelerated intestinal epithelial cell turnover: A new mechanism of parasite expulsion. Science, 308(5727), 1463-1465. doi: 10.1126/science. 1108661

Colinot, D. L., Garbuz, T., Bosland, M. C., Wang, L., Rice, S. E., Sullivan, W. J. Jr., Arrizabalaga, G., \& Jerde, T. J. (2017) The common parasite Toxoplasma gondii induces prostatic inflammation and microglandular hyperplasia in a mouse model. Prostate, 77(10), 1066-1075. doi: 10.1002/pros.23362

Colorni, A., \& Padrós, F. (2011) Diseases and health management. Sparidae: biology and aquaculture of gilthead sea bream and other species. Wiley-Blackwell, London.

Crosnier, C., Stamataki, D., \& Lewis, J. (2006) Organizing cell renewal in the intestine: stem cells, signals and combinatorial control. Nature Reviews Genetics, 7(5), 349-359. doi: $10.1038 / \operatorname{nrg} 1840$ 
526 Cuadrado, M. (2009) Enteromixosi produïda per Enteromyxum leei (Diamant, Lom i

527

528

529

530

531

532

533

534

535

536

537

538

539

540

541

542

543

544

545

546

547

548

549

550 Dyková, 1994) en espàrids d'interès comercial del Mediterrani. Dissertation, Universitat Autònoma de Barcelona.

da Silva, M. S., Muñoz, P. A., Armelin, H. A., \& Elias, M. C. (2017) Differences in the detection of BrdU/EdU incorporation assays alter the calculation for G1, S, and G2 phases of the cell cycle in trypanosomatids. Journal of Eukaryotic Microbiology, doi:10.1111/jeu.12408

Davey, G. C., Calduch-Giner, J. A., Houeix, B., Talbot, A., Sitjà-Bobadilla, A., Prunet, P., Pérez-Sánchez, J., \& Cairns, M. T. (2011) Molecular profiling of the gilthead sea bream (Sparus aurata L.) response to chronic exposure to the myxosporean parasite Enteromyxum leei. Molecular Immunology, 48(15-16), 2102-2112. doi: 10.1016/j.molimm.2011.07.003

Dezfuli, B. S., Bosi, G., DePasquale, J. A., Manera, M., \& Giari, L. (2016a) Fish innate immunity against intestinal helminths. Fish and Shellfish Immunology, 50, 274287. doi: 10.1016/j.fsi.2016.02.002

Dezfuli, B. S., Giari, L., Lui, A., Squerzanti, S., Castaldelli, G., Shinn, A. P., Manera, M., \& Lorenzoni, M. (2012) Proliferative cell nuclear antigen (PCNA) expression in the intestine of Salmo trutta trutta naturally infected with an acanthocephalan. Parasites \& Vectors, 5, 198. doi: 10.1186/1756-3305-5-198

Dezfuli, B. S., Manera, M., Bosi, G., DePasquale, J. A., D'Amelio, S., Castaldelli, G., \& Giari, L. (2016b) Anguilla anguilla intestinal immune response to natural infection with Contracaecum rudolphii A larvae. Journal of Fish Diseases, 39(10), 1187-1200. doi: 10.1111/jfd.12455

Diamant, A. (1997) Fish-to-fish transmission of a marine myxosporean . Diseases of Aquatic Organisms, 30:99-105. doi: 10.3354/dao030099 
551 Diamant, A. Lom, J., Dyková, I. (1994) Myxidium leei n. sp., a pathogenic myxosporean

552

553

554

555

556

557

558

559

560

561

562

563

564

565

566

567

568

569

570

571

572

573

574 of cultured sea bream Sparus aurata. Diseases of Aquatic Organisms, 20:137141. doi: 10.3354/dao020137

Droguett, D., Carrillo, I., Castillo, C., Gómez, F., Negrete, M., Liempi, A., Muñoz, L., Galanti, N., Maya, J. D., \& Kemmerling, U. (2017) Trypanosoma cruzi induces cellular proliferation in the trophoblastic cell line. Experimental Parasitology, 173, 9-17. doi: 10.1016/j.exppara.2016.12.005

Estensoro, I., Jung-Schroers, V., Álvarez-Pellitero, P., Steinhagen, D., \& SitjàBobadilla, A. (2013) Effects of Enteromyxum leei (Myxozoa) infection on gilthead sea bream (Sparus aurata) (Teleostei) intestinal mucus: glycoprotein profile and bacterial adhesion. Parasitology Research, 112(2), 567-576. doi: $10.1007 / \mathrm{s} 00436-012-3168-3$

Estensoro, I., Mulero, I., Redondo, M. J., Álvarez-Pellitero, P., Mulero, V., \& SitjàBobadilla, A. (2014) Modulation of leukocytic populations of gilthead sea bream (Sparus aurata) by the intestinal parasite Enteromyxum leei (Myxozoa: Myxosporea) Parasitology, 141(3), 425-440. doi: 10.1017/S0031182013001789

Estensoro, I., Redondo, M. J., Álvarez-Pellitero, P., \& Sitjà-Bobadilla, A. (2010) Novel horizontal transmission route for Enteromyxum leei (Myxozoa) by anal intubation of gilthead sea bream Sparus aurata. Diseases of Aquatic Organisms, 92(1), 51-58. doi: 10.3354/dao02267

Estensoro, I., Redondo, M. J., Salesa, B., Kaushik, S., Pérez-Sánchez, J., \& SitjàBobadilla, A. (2012) Effect of nutrition and Enteromyxum leei infection on gilthead sea bream Sparus aurata intestinal carbohydrate distribution. Diseases of Aquatic Organisms, 100(1), 29-42. doi: 10.3354/dao02486 
575 Faro, A., Boj, S. F., \& Clevers, H. (2009) Fishing for intestinal cancer models: unraveling gastrointestinal homeostasis and tumorigenesis in zebrafish. Zebrafish, 6(4), 361-376. doi: 10.1089/zeb.2009.0617

Feist, S. W., Morris, D., Alama-Bermejo, G., \& Holzer, A. S. (2015) Cellular Processes in Myxozoans. In: Okamura B, Gruhl A, Bartholomew J (eds) Myxozoan Evolution, Ecology and Development. Springer International Publishing, Switzerland.

Fleurance, R., Sauvegrain, C., Marques, A., Le Breton, A., Guereaud, C., Cherel, Y., \& Wyers, M. (2008) Histopathological changes caused by Enteromyxum leei infection in farmed sea bream Sparus aurata. Diseases of Aquatic Organisms, 79(3), 219-228. doi: 10.3354/dao01832

Foox, J., \& Siddall, M. E. (2015) The road to Cnidaria: History of phylogeny of the Myxozoa. Journal of Parasitology, 101(3), 269-274. doi: 10.1645/14-671.1

Galanti, S. E., Huang, S. C. C., \& Pearce, E. J. (2012) Cell death and reproductive regression in female Schistosoma mansoni. PLOS Neglected Tropical Diseases, 6(2), e1509. doi: 10.1371/journal.pntd.0001509

Goodlad, R. A. (2017) Quantification of epithelial cell proliferation, cell dynamics, and cell kinetics in vivo. Wiley Interdisciplinary Reviews: Developmental Biology, 6, e274. doi: 10.1002/wdev.274

Gratzner, H. G. (1982) Monoclonal antibody to 5-bromo- and 5-iododeoxyuridine: A new reagent for detection of DNA replication. Science, 218(4571), 474-475.

Hemmer, N., Steinhagen, D., Drommer, W., \& Korting, W. (1998) Changes of intestinal epithelial structure and cell turnover in carp Cyprinus carpio infected with Goussia carpelli (Protozoa: Apicomplexa). Diseases of Aquatic Organisms, 34(1), 39-44. doi: 10.3354/dao034039 
Johnson, T. S., Nakatani, R. E., \& Conte, E. P. (1970) Influence of temperature and Xirradiation on cellular dynamics of intestinal epithelium in coho salmon, Oncorhynchus kisutch. Radiation Research, 42(1), 129-140. doi: $10.2307 / 3572923$

Kania, P. W., Evensen, O., Larsen, T. B., \& Buchmann, K. (2010) Molecular and immunohistochemical studies on epidermal responses in Atlantic salmon Salmo salar L. induced by Gyrodactylus salaris Malmberg, 1957. Journal of Helminthology, 84(2), 166-172. doi: 10.1017/S0022149X09990460

Kim, M., Ashida, H., Ogawa, M., Yoshikawa, Y., Mimuro, H., \& Sasakawa, C. (2010) Bacterial interactions with the host epithelium. Cell Host \& Microbe, 8(1), 2035. doi: 10.1016/j.chom.2010.06.006

Krogdahl, Å., Bakke-McKellep, A. M., \& Baeverfjord, G. (2003) Effects of graded levels of standard soybean meal on intestinal structure, mucosal enzyme activities, and pancreatic response in Atlantic salmon (Salmo salar L.). Aquaculture Nutrition, 9(6), 361-371. doi: 10.1046/j.1365-2095.2003.00264.x

Liempi, A., Castillo, C., Carrillo, I., Muñoz, L., Droquett, D., Galanti, N., Maya, J. D., \& Kemmerling, U. (2016) A local innate immune response against Trypanosoma cruzi in the human placenta: The epithelial turnover of the trophoblast. Microbial Pathogenesis, 99, 123-129. doi: 10.1016/j.micpath.2016.08.022

Livak, K. J., \& Schmittgen, T. D. (2001) Analysis of relative gene expression data using real-time quantitative PCR and the $2^{-\Delta \Delta \mathrm{Ct}}$ method. Methods, 25(4), 402-408. doi: 10.1006/meth.2001.1262

Losada, A. P., Bermúdez, R., Faílde, L. D., Ruiz de Ocenda, M. V., \& Quiroga, M. I. (2014) Study of the distribution of active caspase-3-positive cells in turbot, 
Scophthalmus maximus (L.), enteromyxosis. Journal of Fish Diseases, 37(1), 21-32. doi: 10.1111/jfd.12029

627

628

629

630

631

632

633

634

635

636

637

638

639

640

641

642

643

644

645

646

647

648

649

Mailand, N., Gibbs-Seymour, I., \& Bekker-Jensen, S. (2013) Regulation of PCNAprotein interactions for genome stability. Nature Reviews Molecular Cell Biology, 14(5), 269-282. doi: 10.1038/nrm3562

Mandell, M. A., \& Beverley, S. M. (2017) Continual renewal and replication of persistent Leishmania major parasites in concomitantly immune hosts. Proceedings fo the National Academy of Science of the United States of America, 114(5), E801-E810. doi: 10.1073/pnas.1619265114.

Merrick, C. J. (2015) Transfection with thymidine kinase permits bromodeoxyuridine labelling of DNA replication in the human malaria parasite Plasmodium falciparum. Malaria Journal, 14, 490. doi: 10.1186/s12936-015-1014-7

Morris, D. J. (2010) Cell formation by myxozoan species is not explained by dogma. Proceedings of the Royal Society B: Biological Sciences, 277(1693), 2565-2570. doi: 10.1098/rspb.2010.0282

Mysorekar, I. U., Mulvey, M. A., Hultgren, S. J., \& Gordon, J. I. (2002) Molecular regulation of urothelial renewal and host defenses during infection with uropathogenic Escherichia coli. The Journal of Biological Chemistry, 277(9), 7412-7419. doi: 10.1074/jbc.M110560200

Palenzuela, O. (2006) Myxozoan infections in Mediterranean mariculture. Parassitologia, 48(1-2), 27-29.

Pérez-Cordón, G., Estensoro, I., Benedito-Palos, L., Calduch-Giner, J. A., SitjàBobadilla, A., \& Pérez-Sánchez, J. (2014) Interleukin gene expression is strongly modulated at the local level in a fish-parasite model. Fish and Shellfish Immunology, 37(2), 201-208. doi: 10.1016/j.fsi.2014.01.022 
Pérez-Sánchez, J., Estensoro, I., Redondo, M. J., Calduch-Giner, J. A., Kaushik, S., \& Sitjà-Bobadilla, A. (2013) Mucins as diagnostic and prognostic biomarkers in a fish-parasite model: transcriptional and functional analysis. PLoS One, 8(6), e65457. doi: 10.1371/journal.pone.0065457

Redondo, M. J., Palenzeula, O., \& Álvarez-Pellitero, P. (2003) In vitro studies on viability and proliferation of Enteromyxum scophthalmi (Myxozoa), an enteric parasite of cultured turbot Scophthalmus maximus. Diseases of Aquatic Organisms, 55(2), 133-144. doi: 10.3354/dao055133

Reichard, P. (1988) Interactions between deoxyribonucleotide and DNA-synthesis. Annual Review of Biochemistry, 57, 349-374. doi: 10.1146/annurev.bi.57.070188.002025

Rigos, G., \& Katharios, P. (2010) Pathological obstacles of newly-introduced fish species in Mediterranean mariculture: A review. Reviews in Fish Biology and Fisheries, 20(1), 47-70. doi: 10.1007/s11160-009-9120-7

Robledo, D., Ronza, P., Harrison, P. W., Losada, A. P., Bermúdez, R., Pardo, B. G., Redondo, M. J., Sitjà-Bobadilla, A., Quiroga, M. I., \& Martínez, P. (2014) RNA-seq analysis reveals significant transcriptome changes in turbot (Scophthalmus maximus) suffering severe enteromyxosis. BMC Genomics, 15, 1149. doi: 10.1186/1471-2164-15-1149

Ronza, P., Bermúdez, R., Losada, A. P., Robles, A., \& Quiroga, M. I. (2011) Mucosal $\mathrm{CD} 3 \varepsilon+$ cell proliferation and gut epithelial apoptosis: Implications in rainbow trout gastroenteritis (RTGE). Journal of Fish Diseases, 34(6), 433-443. doi: 10.1111/j.1365-2761.2011.01254.x

Ronza, P., Robledo, D., Bermúdez, R., Losada, A. P., Pardo, B. G., Sitjà-Bobadilla, A., Quiroga, M. I., \& Martínez, P. (2016) RNA-seq analysis of early enteromyxosis 
in turbot (Scophthalmus maximus): New insights into parasite invasion and immune evasion strategies. International Journal for Parasitology, 46(8), 507517. doi: 10.1016/j.ijpara.2016.03.007

Savage, D. C., Siegel, J. E., Snellen, J. E., \& Whitt, D. D. (1981) Transit time of epithelial cells in the small intestines of germfree mice and ex-germfree mice associated with indigenous microorganisms. Applied and Environmental Microbiology, 42(6), 996-1001.

Schall, K. A., Holoyda, K. A., Grant, C. N., Levin, D. E., Torres, E. R., Maxwell, A., Pollack, H. A., Moats, R. A., Frey, M. R., Darehzereshki, A., Al Alam, D., Lien, C., \& Grikscheit, T. C. (2015) Adult zebrafish intestine resection: a novel model of short bowel syndrome, adaptation, and intestinal stem cell regeneration. American Journal of Physiology: Gastrointestinal and Liver Physiology, 309(3), G135-G145. doi: 10.1152/ajpgi.00311.2014

Sitjà-Bobadilla, A. (2004) Parasites in Mediterranean aquacultured fish: Current impact and future research directions. In: Multidisciplinarity for Parasites, Vectors and Parasitic Diseases Vol 1 (Mas-Coma S. Ed.). Medimond, Bologna, Italy.

Sitjà-Bobadilla, A., Calduch-Giner, J., Saera-Vila, A., Palenzuela, O., Álvarez-Pellitero, P., \& Pérez-Sánchez, J. (2008) Chronic exposure to the parasite Enteromyxum leei (Myxozoa: Myxosporea) modulates the immune response and the expression of growth, redox and immune relevant genes in gilthead sea bream, Sparus aurata L. Fish and Shellfish Immunology, 24(5), 610-619. doi: 10.1016/j.fsi.2008.01.014

Sitjà-Bobadilla, A., Estensoro, I., \& Pérez-Sánchez, J. (2016) Immunity to gastrointestinal microparasites of fish. Developmental and Comparative Immunology, 64, 187-201. doi: 10.1016/j.dci.2016.01.014 
Sitjà-Bobadilla, A., \& Palenzuela, O. (2012) Enteromyxum species Fish Parasites: Pathology and Protection, (eds) Woo PTK \& Buchmann K, CAB International, Oxfordshire UK, pp 163-176

Takahashi, H., Prunet, P., Kitahashi, T., Kajimura, S., Hirano, T., Grau, E. G., \& Sakamoto, T. (2007) Prolactin receptor and proliferating/apoptotic cells in esophagus of the Mozambique tilapia (Oreochromis mossambicus) in fresh water and in seawater. General and Comparative Endocrinology, 152(2-3), 326331. doi: 10.1016/j.ygcen.2007.02.021

Takahashi, H., Sakamoto, T., \& Narita, K. (2006) Cell proliferation and apoptosis in the anterior intestine of an amphibious, euryhaline mudskipper (Periophthalmus modestus). Journal of Comparative Physiology B, 176(5), 463-468. doi: $10.1007 / \mathrm{s} 00360-006-0067-\mathrm{x}$

Walsh, E., \& Eckert, K. A. (2014) Eukaryotic replicative DNA polymerases. In: Murakami KS, Trakselis MA (eds) Nucleic Acid Polymerases. Springer Berlin Heidelberg, Berlin, Heidelberg, pp 17-4.

Wallace, K. N., Akhter, S., Smith, E. M., Lorent, K., \& Pack, M. (2005) Intestinal growth and differentiation in zebrafish. Mechanisms of Development, 122(2), 157-173. doi: 10.1016/j.mod.2004.10.009

Wang, Z., Matsudaira, P., \& Gong, Z. (2010) STORM: A general model to determine the number and adaptive changes of epithelial stem cells in teleost, murine and human intestinal tracts. PLoS One, 5(11), e14063. doi: 10.1371/journal.pone.0014063

Yoshida, C., Maekawa, M., Bannai, M., \& Yamamoto, T. (2016) Glutamate promotes nucleotide synthesis in the gut and improves availability of soybean meal feed in rainbow trout. Springerplus, 5(1), 1021. doi: 10.1186/s40064-016-2634-2 
Table 1 Enteromyxum leei infection in gilthead sea bream in the anterior (AI), middle

727 (MI) and posterior (PI) intestinal segments at two sampling times: t1 at 17 days post intubation (dpi), and t2 at 64 dpi. Infection intensity is indicated with a semiquantitative conventional scale.

$$
\text { t1 }(n=7) \quad \text { t2 }(n=7)
$$

\begin{tabular}{lccccccc}
\hline Intestinal segment & AI & MI & PI & & AI & MI & PI \\
Prevalence of infection (\%) & 14.3 & 0 & 42.9 & 57.1 & 14.3 & 85.7 \\
Mean intensity of infection & $2+$ & - & $2+$ & $3.3+$ & $6+$ & $5.2+$
\end{tabular}

731

732 Figure legends

733

734 Fig. 1 Giemsa staining (a-c) and BrdU immunodetection (d-g) in gilthead sea bream intestinal sections. Non-parasitized (d) and Enteromyxum leei-parasitized (a-c, e, g) recipient fish sections; control non-infected fish intestinal section (f). Proliferative parasite stages (white arrowheads) were detected in t1 (a) and disporoblasts with mature spores (black arrowheads) in $\mathrm{t} 2$ (b). Note the hyperplasia of the lamina propiasubmucosa (c) and the presence of immunoreactive cells $(d, e)$ and parasite stages (e, asterisks) in the epithelium. Immunoreactive epithelial cells reaching the mucosal fold tips (arrowheads) in a control intestinal section (f). E. leei stages (arrows) with

742 immunoreactive daughter cells in the intestinal epithelium (g). Scale bars $=20 \mu \mathrm{m}$.

744 Fig. 2 BrdU immunodetection in the intestine of control uninfected (CTRL) and 745 recipient (RCPT) gilthead sea bream experimentally infected with Enteromyxum leei at 

intestinal sections are shown. Scale bars $=50 \mu \mathrm{m}$.

Fig. 3 Number of BrdU immunolabelled intestinal cells (mean + SEM, $n=7$ ) at time 1 (t1, 17 dpi) and time 2 (t2, 64 dpi) in control (CTRL) and recipient (RCPT) gilthead sea bream experimentally infected with Enteromyxum leei. Equal upper or lower case letters indicate no statistical significant differences among intestinal segments (anterior (AI), middle (MI), posterior (PI)) within each group. Asterisks indicate statistical significant differences between CTRL and RCPT fish within each intestinal segment ${ }^{*}=P<0.05$; $* *=P<0.001)$.

756

Fig. 4 Number of BrdU immunolabelled intestinal cells (mean + SEM) at the anterior, middle and posterior intestinal segments for pooled data from $\mathrm{t} 1$ and $\mathrm{t} 2$. Four fish categories were created according to the presence of Enteromyxum leei: control (CTRL); RCPT fish non-parasitized at any segment (NP); RCPT fish non-parasitized at anterior or middle intestines, but parasitized at the posterior intestine (NP-PAR PI); RCPT fish parasitized AI/MI and also parasitized at PI (PAR). Different letters indicate statistically significant differences $(P<0.05)$ among fish categories within each intestinal segment. The red arrows above each segment indicate the mean fold increase between CTRL and PAR fish.

766

767 Fig. 5 pcna gene expression in the posterior intestine (PI), spleen (Spl) and head kidney (Hk) of recipient (RCPT) gilthead sea bream experimentally infected with Enteromyxum leei, at $\mathrm{t} 1$ and $\mathrm{t} 2$ samplings (mean $+\mathrm{SEM}, n=6$ fish). Fold changes are relative to each 
770 time point control, represented by the dotted line at $y=1$. Asterisk (*) indicates

771 statistically significant difference with the respective time point control $(P<0.05)$. 


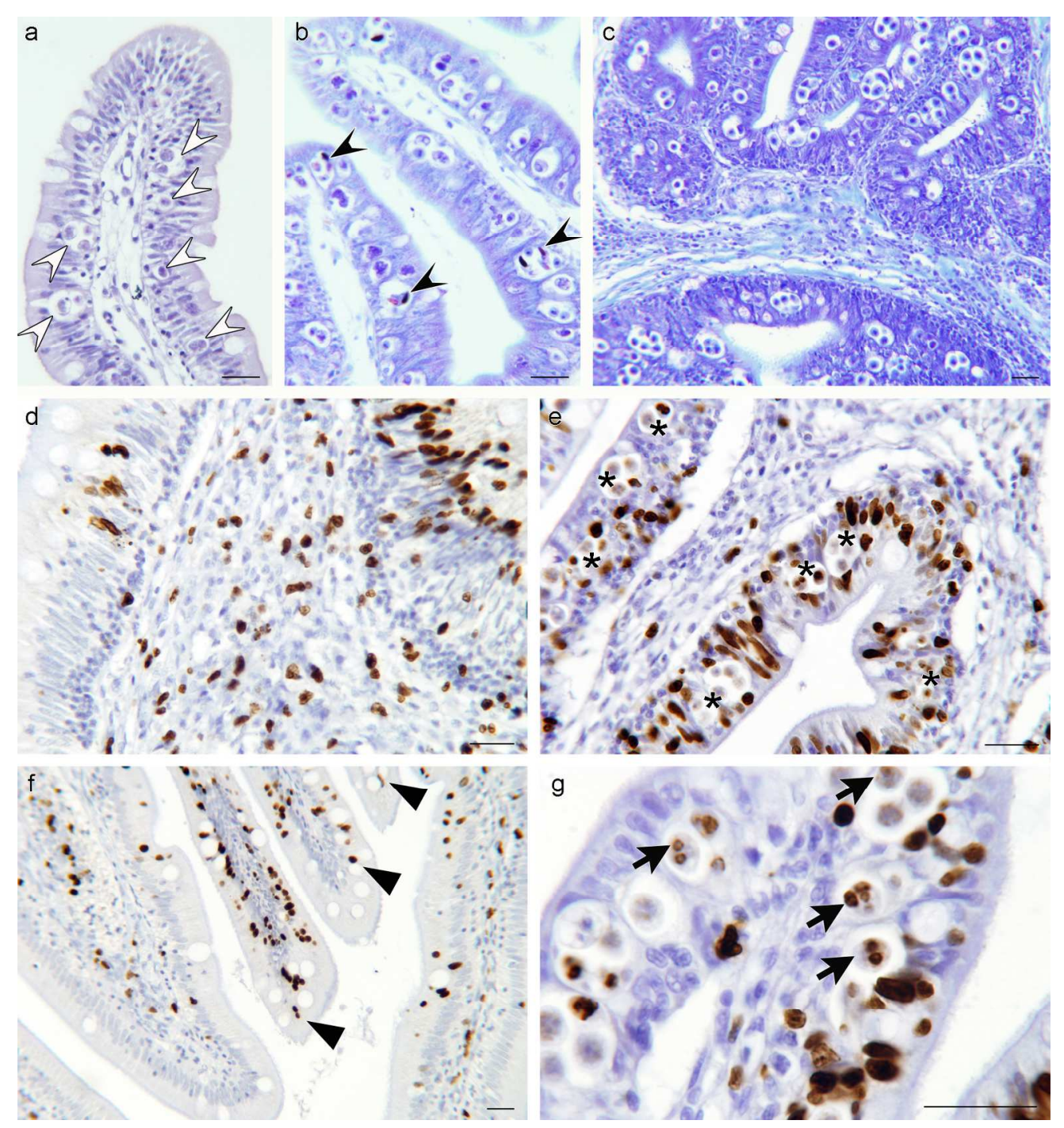

Fig. 1 Giemsa staining (a-c) and BrdU immunodetection ( $d-g)$ in gilthead sea bream intestinal sections. Nonparasitized (d) and Enteromyxum leei-parasitized $(a-c, e, g)$ recipient fish sections; control non-infected fish intestinal section (f). Proliferative parasite stages (white arrowheads) were detected in $t 1$ (a) and disporoblasts with mature spores (black arrowheads) in t2 (b). Note the hyperplasia of the lamina propiasubmucosa (c) and the presence of immunoreactive cells (d, e) and parasite stages (e, asterisks) in the

epithelium. Immunoreactive epithelial cells reaching the mucosal fold tips (arrowheads) in a control intestinal section (f). E. leei stages (arrows) with immunoreactive daughter cells in the intestinal epithelium (g). Scale bars $=20 \mu \mathrm{m}$.

$173 \times 185 \mathrm{~mm}(300 \times 300 \mathrm{DPI})$ 


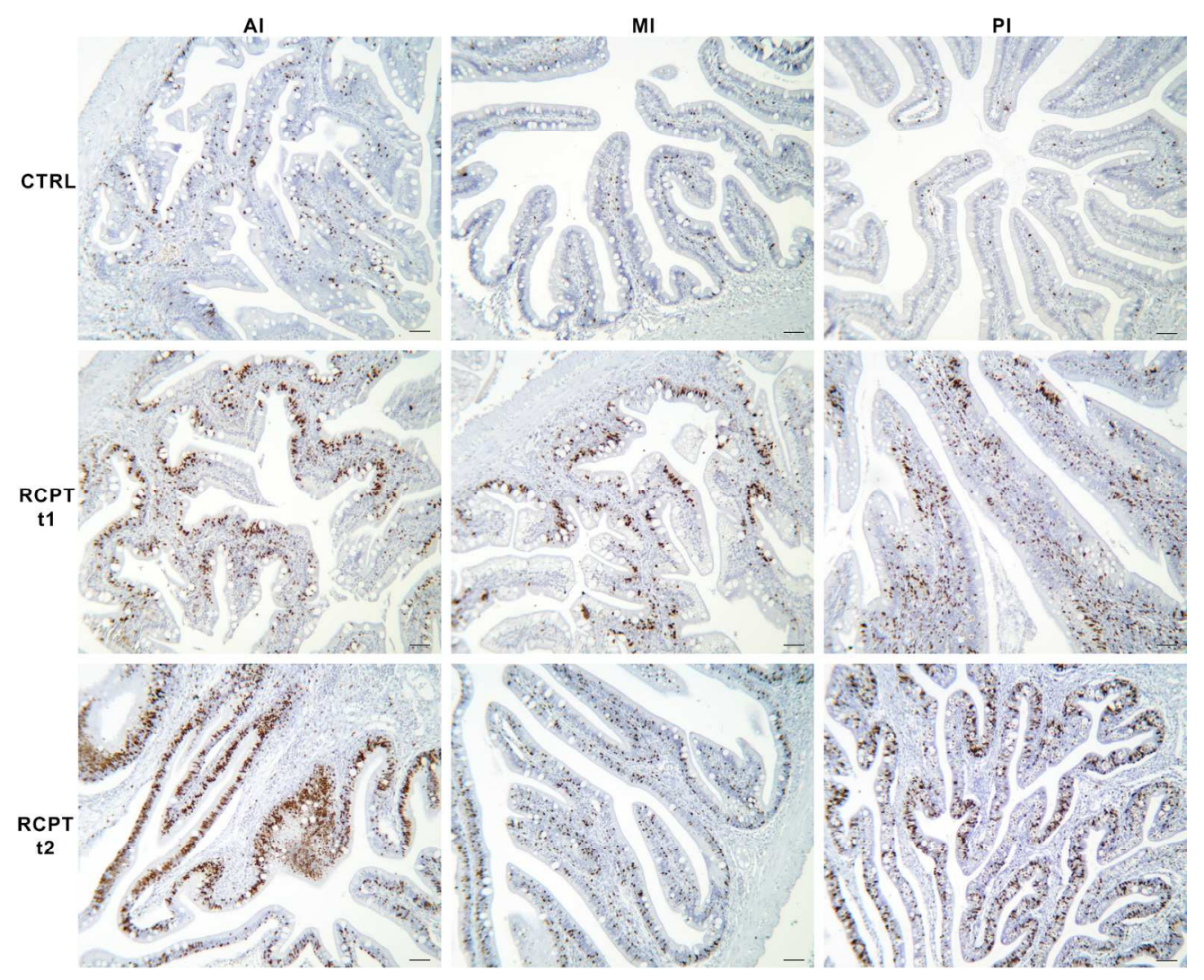

Fig. $2 \mathrm{BrdU}$ immunodetection in the intestine of control uninfected (CTRL) and recipient (RCPT) gilthead sea bream experimentally infected with Enteromyxum leei at 17 (t1) and 64 (t2) days post intubation. Anterior $(\mathrm{AI})$, middle (MI) and posterior (PI) intestinal sections are shown. Scale bars $=50 \mu \mathrm{m}$.

$173 \times 142 \mathrm{~mm}(300 \times 300$ DPI $)$ 


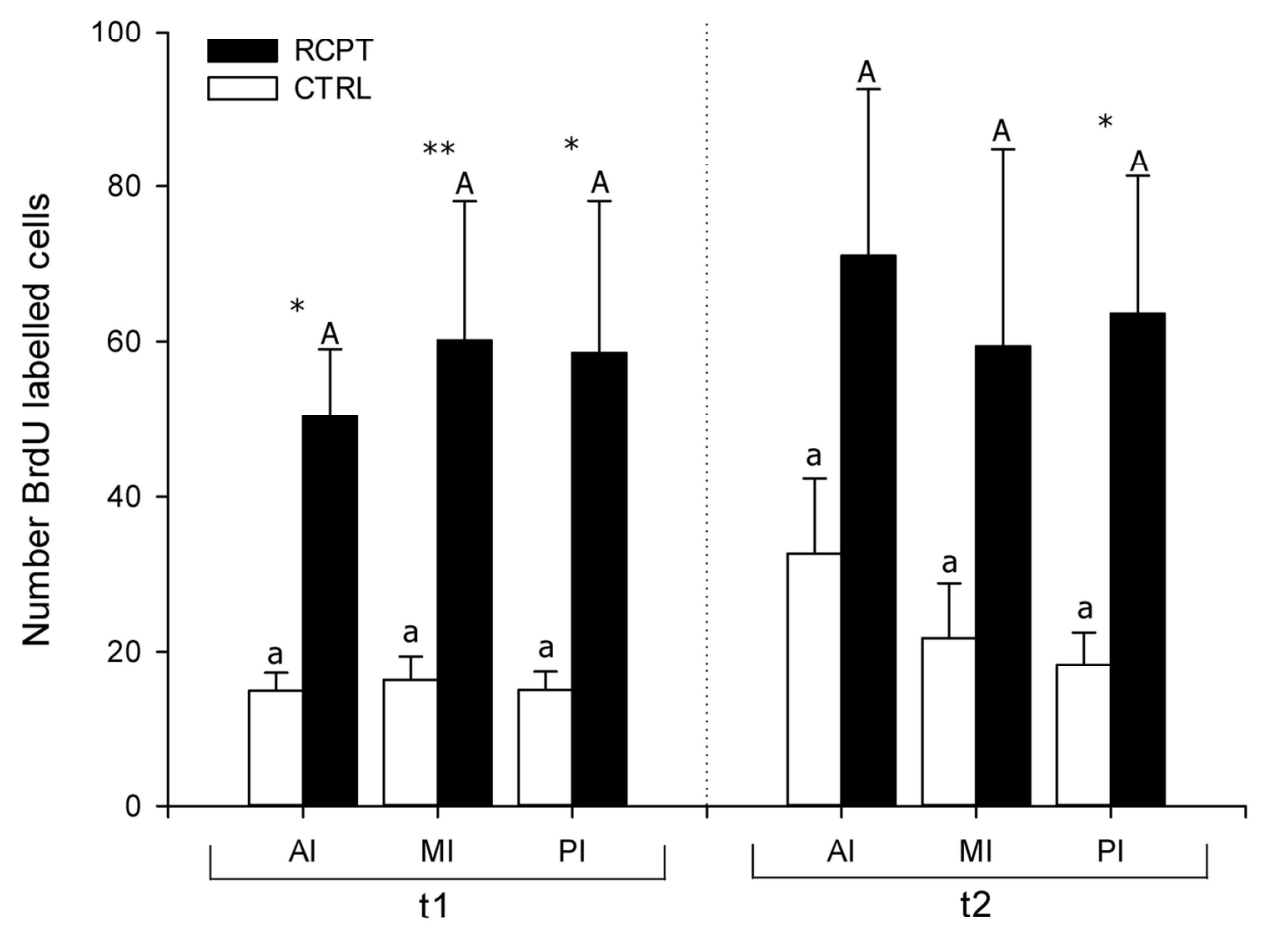

Fig. 3 Number of BrdU immunolabelled intestinal cells (mean $+\mathrm{SEM}, \mathrm{n}=7$ ) at time 1 (t1, $17 \mathrm{dpi}$ ) and time 2 ( $t 2,64 \mathrm{dpi})$ in control (CTRL) and recipient (RCPT) gilthead sea bream experimentally infected with Enteromyxum leei. Equal upper or lower case letters indicate no statistical significant differences among intestinal segments (anterior (AI), middle (MI), posterior (PI)) within each group. Asterisks indicate statistical significant differences between CTRL and RCPT fish within each intestinal segment $(*=P<0.05$; $* *=\mathrm{P}<0.001$ ).

$130 \times 113 \mathrm{~mm}(300 \times 300 \mathrm{DPI})$ 


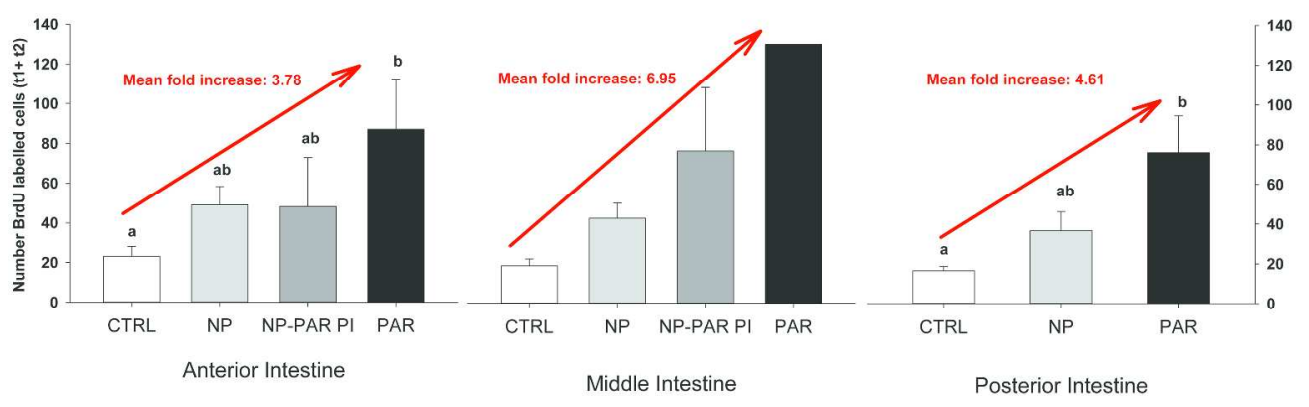

Fig. 4 Number of BrdU immunolabelled intestinal cells (mean + SEM) at the anterior, middle and posterior intestinal segments for pooled data from $\mathrm{t} 1$ and $\mathrm{t} 2$. Four fish categories were created according to the presence of Enteromyxum leei: control (CTRL); RCPT fish non-parasitized at any segment (NP); RCPT fish non-parasitized at anterior or middle intestines, but parasitized at the posterior intestine (NP-PAR PI); RCPT fish parasitized AI/MI and also parasitized at PI (PAR). Different letters indicate statistically significant differences $(P<0.05)$ among fish categories within each intestinal segment. The red arrows above each segment indicate the mean fold increase between CTRL and PAR fish.

$296 \times 104 \mathrm{~mm}(300 \times 300$ DPI) 


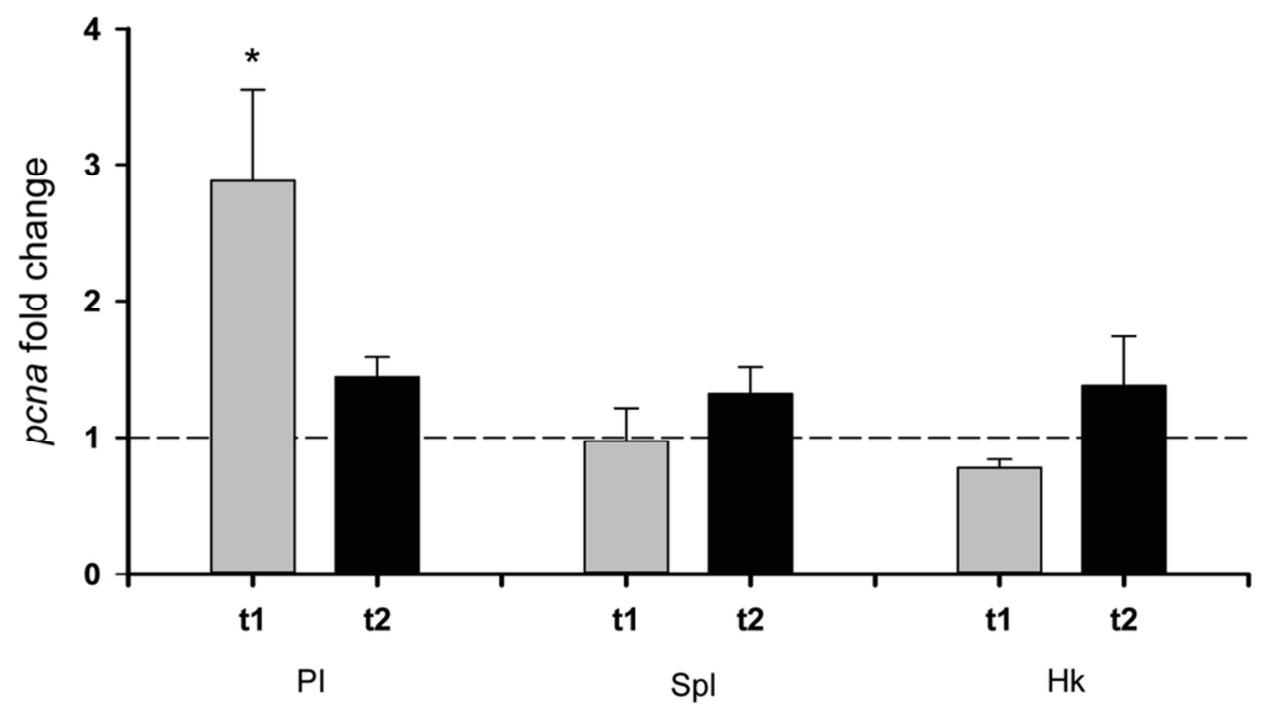

Fig. 5 pcna gene expression in the posterior intestine (PI), spleen (Spl) and head kidney (Hk) of recipient (RCPT) gilthead sea bream experimentally infected with Enteromyxum leei, at $\mathrm{t} 1$ and $\mathrm{t} 2$ samplings (mean + $\mathrm{SEM}, \mathrm{n}=6 \mathrm{fish}$ ). Fold changes are relative to each time point control, represented by the dotted line at $\mathrm{y}=$ 1. Asterisk $\left(^{*}\right)$ indicates statistically significant difference with the respective time point control $(P<0.05)$.

$88 \times 54 \mathrm{~mm}(300 \times 300$ DPI $)$ 